\title{
Antihypercholesterolemic and Antioxidant Effects of Blumea balsamifera L. Leaf Extracts to Maintain Luteinizing Hormone Secretion in Rats Induced by High-Cholesterol Diets
}

\author{
I Gede Widhiantara ${ }^{1, *}$, Anak Agung Ayu Putri Permatasari ${ }^{1}$, I Wayan Rosiana ${ }^{1}$, \\ Putu Angga Wiradana ${ }^{1}$, Luh Putu Widiastini ${ }^{2}$, I Made Jawi ${ }^{3}$ \\ ${ }^{1}$ Study Program of Biology, Faculty of Health, Science, and Technology, Universitas Dhyana Pura, Jl. Raya Padangluwih, \\ Badung 80361, Bali, Indonesia \\ ${ }^{2}$ Study Program of Midwifery, Institute of Health Science-Bina Usada, Jl. Raya Padang Luwih, Badung 80361, Bali, Indonesia \\ ${ }^{3}$ Department of Pharmacology, Faculty of Medicine, Universitas Udayana, Jl. P.B. Sudirman, Denpasar 80234, Bali, Indonesia \\ *Corresponding author. E-mail: widhiantara@undhirabali.ac.id
}

Received date: Aug 27, 2021; Revised date: Nov 10, 2021; Accepted date: Nov 11, 2021

\section{Abstract}

$\mathrm{B}$ ACKGROUND: The discovery of herbal ingredients for antihypercholesterolemic and to improve male reproductive function is very necessary due to high-cholesterol diet factors. Blumea balsamifera leaf extract (BBLE) is known to be able to increase the number and diameter of Leydig cells in rats given high-fat feed. This study was to conducted to determine the levels of total cholesterol, body weight, plasma malondialdehyde (MDA), Superoxide Dismutase (SOD), Luteinizing Hormone (LH) in high-cholesterol-fed male rats provided with BBLE.

METHODS: This research utilized a randomized post-test only control group. Ethanol was used to extract the BBLE, which was then evaporated. For 21 days, 16 Wistar rats were given a high-cholesterol diet. To determine the effect of BBLE on the high-cholesterol diet, the samples were divided into two groups (control and BBLE group) on day
22. The treatments lasted 30 days. SOD, plasma MDA, LH, and total cholesterol were measured.

RESULTS: The results showed that the SOD and LH parameters were significantly higher in the treatment of BBLE compared to the control group $(p<0.05)$. The parameters of total cholesterol levels, bodyweight, and MDA of rats given BBLE were significantly lower than those of the control group $(p<0.05)$.

CONCLUSION: Our findings highlight that BBLE has antihypercholesterolemic and antioxidant effects. The BBLE also has potential to be used as a therapy to maintain male reproductive function because it has a positive effect on the hypothalamic-pituitary axis through increasing $\mathrm{LH}$ secretion.

KEYWORDS: Malondialdehyde, Superoxide dismutase, Luteinizing hormone, Blumea balsamifera extract, Highcholesterol diet

Indones Biomed J. 2021; 13(4): 396-402

\section{Introduction}

Increased levels of cholesterol in the blood, known as hypercholesterolemia, is linked to a variety of health issues, including diabetes, cancer, and obesity, as well as having an influence on reproductive abnormalities.
Hypercholesterolemic is characterized by oxidative stress caused by elevated malondialdehyde (MDA) levels and reduced superoxide dismutase (SOD). MDA, on the other hand, is an oxidative damage marker of physiological cell damage.(1) A study showed that the hypercholesterolemic group had higher plasma MDA concentrations than the nonhypercholesterolemic group. This indicates the correlation 
between oxidative stress and hypercholesterolemic progression.(2) As a result, the availability of antioxidant ingredients is critical in maintaining a balance between antioxidant enzymes and oxidative stress levels (3-6), especially in people with hypercholesterolemic.

At the tissue level, hypercholesterolemic increases reactive oxygen species (ROS) production and the lipid peroxide formation imbalance. $(7,8)$ Oxidative stress may also cause disruption of the hypothalamic-pituitary-testis axis in the male reproductive system, resulting in reduced luteinizing hormone release. This disorder causes a reduction in Leydig cells number in the testes as well as an impairment of the spermatogenesis process.(9) Our previous study showed a significant reduction in the number of Leydig cells, spermatogonia A cells, primary spermatocytes, spermatids 7, spermatids 16, and Corvus cavernosum muscle thickness significantly in rats induced by a high-cholesterol diet for 50 days.(10) The administration of a high-fat diet also significantly decreased the lumen diameter and thickness of the dorsal penile artery endothelium in Wistar rats.(11)

Sembung (Blumea balsamifera) is a traditional plant with a high antioxidant content and is commonly used as a traditional medicine in Indonesia and many other Asian countries.(12) B. balsamifera leaf is mostly used to make a traditional drink called "Loloh" by Balinese people in Indonesia. B. balsamifera contains bioactive substances such as essential oils (cineol, borneol, landerol, and camphor), flavonols, tannins, resin, and cantoxillin. The flavonoid compounds can serve as immunomodulators and antioxidants preventing the body from producing so much oxidative stress.(13) The results of our preliminary research indicate that $B$. balsamifera leaf extract (BBLE) is able to increase the number and diameter of Leydig cells in rats given high-fat feed.(14)

Based on the above information, this study aims to study the antihypercholesterolemic and antioxidant potential of BBLE and their relation to the improvement of the work of the hypothalamic-pituitary axis in secreting Luteinizing Hormone (LH). This findings may be utilized to develop pharmacological formulations, particularly for the treatment of male infertility related with hypercholesterolemic risk factors.

\section{Methods}

\section{Research Design}

This study was included in an experimental study with a randomized post-test only control group design. As much as 16 rats were taken randomly and divided into 2 groups, namely the control group (high-cholesterol feed and sterile distilled water) and the BBLE group (high-cholesterol feed and $4 \mathrm{mg} / \mathrm{mL} / \mathrm{BW}$ rats of BBLE orally) daily for 30 days. The treatment dosage was determined based on a previous study $(15,16)$ which was converted to rats.

\section{Preparation of BBLE}

B. balsamifera plants were obtained from plantations in Luwus Village, Tabanan Regency, Bali, which had previously been identified/determined at the Indonesian Institute of Science (Lembaga Ilmu Pengetahuan Indonesia/LIPI), Bali Botanic Garden, Candikuning, Baturiti, Tabanan, Bali. The extraction process follows the extraction method described in previous studies.(14) Fresh B. balsamifera leaves were washed, dried, and crushed using a blender. A total of 250 grams of B. balsamifera powder was then macerated for 24 hours in ethanol. The ethanol as solvent was macerated for 24 hours. The macerated extract was furthermore filtered, and the filtrate was concentrated using a rotary evaporator to separate the extract material's alcohol content. The extract was evaporated until forming the thick green sticky paste. The production of BBLE was carried out at the Laboratory of Science, Universitas Dhyana Pura.

\section{Phytochemical Screening and Quantification}

Phytochemical compounds of BBLE, including alkaloids, flavonoids, triterpenoids, saponins, phenols, tannins, and steroids, were analyzed with various methods. Alkaloid constituents was measured by Wagner-Meyer reaction methods (17), flavonoid was screened with $10 \% \mathrm{NaOH}$ solution (18), triterpenoid and steroid screening were conducted with Lieberman-Burchard method (17), saponin screening was conducted based on standard procedure with hot water and $\mathrm{HCl}$ (19), total phenol content was determined by Folin-Ciocalteu method with some modification (18), and for the identification of tannin, $1 \% \mathrm{FeCl}$ was used (20).

Meanwhile, phytochemical quantification of BBLE included the analysis of total phenol (mg/100 g GAE), flavonoids (mg/100 g), and tannin content (mg/100 g TAE). Flavonoid content was measured using standard Aluminium chloride method, while tannin and phenolic content was determined by using Folin-Ciocalteu method.(21) Standard indicator of BBLE was also adjusted to the 2017 Indonesian Herbal Pharmacopoeia Standardization Edition II.(22)

\section{Rat Models and Treatment}

The protocol of this study was approved by The Research Ethics Committee of the Faculty of Medicine, Universitas 
Udayana, and the Sanglah Central General Hospital in Denpasar, Bali (No: 2020.02.2.2.0937). The rat models in this study were adult male Wistar rats (Rattus norvegicus) aged 3-4 months with a body weight of 150-200 g. The rats were taken randomly to get the number of samples and divided into two groups. During the acclimatization phase, rats were given a standard diet that included 20-25\% protein, $5 \%$ fat, $45-50 \%$ starch, $5 \%$ crude fiber, $4 \%$ ash, and vitamins and minerals. While the composition of the highcholesterol diet used in this study contained a mixture of $10 \%$ pork oil, $5 \%$ duck egg yolk, and standard feed.

A high-cholesterol diet and distilled water were given to the control group. Whereas the BBLE group was supplemented a high-cholesterol diet and BBLE of $4 \mathrm{mg} / \mathrm{mL} /$ body weights per day (each rat was given $1 \mathrm{~mL}$ containing $4 \mathrm{mg}$ of extract) for 30 days orally.(16) After 30 days, blood was taken through the orbital sinus for examination of plasma MDA levels, SOD, LH, and total cholesterol.

\section{Total Cholesterol and Body Weight}

Total cholesterol of rats was analyzed using the Cholesterol FS (Catalogue No: 113009910 021, DiaSys Diagnostic Systems, Holzheim, Germany) based on the procedure. In summary, $1 \mathrm{~mL}$ of the sample was centrifuged at 3,000 rpm for 15 minutes. Then, the plasma was taken using a micropipette and put in an Effendorf tube, and stored at $-20^{\circ} \mathrm{C}$. The centrifuged plasma was mixed with the reagent. The entire sample mixture was incubated for $5 \mathrm{~min}$ at $37^{\circ} \mathrm{C}$. Cholesterol levels were read on a spectrophotometer with a wavelength of $500 \mathrm{~nm}$. Calculation of the results according to the following equation (23) : Total cholesterol level = (Sample absorbance) / (Standard absorbance $\times$ Standard concentration).

Rats in both treatments were weighed after 30 days of intervention using $1 \mathrm{~kg}$ analytical balance (Mettler Toledo AL-204 Analytical Balance, Mettler Toledo, Columbus, $\mathrm{OH}$, United States).(24) This was performed to determine body weight mass due to exposure to high-cholesterol feed and BBLE.

\section{Plasma MDA}

MDA levels in plasma were determined using ab238537 (MDAAssay Kit) (Bioassay System, Kampenhout, Belgium). The first two columns currently offer standard solutions. Each concentration was replicated up to $50 \mu \mathrm{L} /$ well. The samples were mixed at the same concentration. Each well-received $50 \mu \mathrm{L}$ of biotinylated detection is a working solution. For 45 minutes at $45^{\circ} \mathrm{C}$, the plates were closed. Then each well-received $350 \mu \mathrm{L}$ wash buffer was soaked for 1-2 minutes and dried sterile. The plates were then cleaned three times and re-incubated at $37^{\circ} \mathrm{C}$ for 30 minutes with a $100 \mu \mathrm{L}$ HRP conjugate working solution. Incubation of each well for 25 minutes at $37^{\circ} \mathrm{C}$ with $90 \mu \mathrm{L}$ of substrate reagent. Then $50 \mu \mathrm{L}$ of stop solution was added to each well. Each well's optical density was measured using an ELISA Reader at $450 \mathrm{~nm}$.

\section{SOD Levels}

SOD levels were checked using the SOD Assay Kit (Catalog No: ESOD-100, Bioassay Systems). In short, $20 \mu \mathrm{L}$ of plasma sample solution was added to each sample and 20 $\mu \mathrm{L}$ of $\mathrm{H}_{2} \mathrm{O}_{2}$ was added to blank 1 and blank $2200 \mu \mathrm{L}$ of WST working solution and $20 \mu \mathrm{L}$ of Dillution buffer were added to each blank. $20 \mu \mathrm{L}$ of Enzyme solution was added to each sample. The well-plates were incubated at $37^{\circ} \mathrm{C}$ for 20 minutes. The absorbance was obtained using a microplate reader at a wavelength of $450 \mathrm{~nm}$. The results obtained were analyzed using the SOD standard in the form of $\mathrm{U} / \mathrm{mL}$.

\section{LH Levels}

The LH levels were measured using the MBS764675 Rat LH ELISA Kit (MyBioSource, San Diego, CA, USA). In brief, all reagents operating standards. It was incubated at $4^{\circ} \mathrm{C}$ with $20 \mu \mathrm{L}$ of standard, control, and sample solutions. Each well got $100 \mu \mathrm{L}$ HRP and $100 \mu \mathrm{L}$ biotin conjugate. The wells were drained and tin-papered. This was followed by an hour of cooling. Then the tin paper was removed and the well was aspirated. It was cleaned 3 times with $300 \mu \mathrm{L}$ $1 \mathrm{X}$ washing solution, soaking for 5 seconds between each wash. After the final wash, the $1 \mathrm{X}$ Washing Solution was aspirated or decanted. With a dry sterile cloth, the surplus liquid was wiped off the plate-wells. Then, all wells were incubated for 15 minutes at room temperature in the dark with $100 \mu \mathrm{L}$ TMB substrate solution. All wells received 100 $\mu \mathrm{L}$ stop solution in the same sequence and pace as the TMB Substrate Solution. The plates were thoroughly shaken. During incubation, the hue changes from blue to yellow. After 30 minutes, the sample's absorbance was measured at $450 \mathrm{~nm}$.

\section{Data Analysis}

The collected data were analyzed using the Statistical Package for the Social Sciences (SPSS) 23 software program (IBM Corporation, Armonk, NY, USA). The results were evaluated using the Independent-Samples T-Test with a confidence interval of $p<0.05$ to determine the significant differences between each treatment. Observation results were displayed in the form of Figures using GraphPad 
Prism 8.0.1 for Windows (GraphPad Software, San Diego, CA USA) and Tables.

\section{Results}

\section{Phytochemical Compounds}

Overall, the results of the phytochemical screening of BBLE used as a treatment in our study were positive for flavonoids, saponins, phenols, tannins, and steroids (Table 1).

Likewise, the quantitative results showed that the highest levels of flavonoid compounds were obtained in the extracted material, namely $22083.88 \mathrm{mg} / 100 \mathrm{~g}(22.083 \%)$, which was not less than $1.31 \%$ (based on the Indonesian Herbal Pharmacopoeia Standardization II edition). Meanwhile the quantification result of total phenol and tannin showed $6820.04 \mathrm{mg} / 100 \mathrm{~g}$ GAE and $696.99 \mathrm{mg} / 100$ g TAE, respectively.

\section{The Effect of BBLE on Total Cholesterol Levels and Body Weight}

There were significant differences $(p<0.05)$ between the both groups based on total cholesterol levels. The control group's average cholesterol level was $72.92 \pm 17.13 \mathrm{mg} / \mathrm{dL}$ higher than the BBLE group, which was $35.86 \pm 1.15 \mathrm{mg} / \mathrm{dL}$ lower (Figure 1). Weight parameters also differed substantially between the two groups $(p<0.05)$. The average bodyweight of the control rats after 30 days of high-cholesterol feeding was up to $272 \pm 9.85$ grams, which was higher than the rats supplemented with BBLE, which was $165.38 \pm 5.73$ grams (Figure 2).

\section{The Effect of BBLE on Plasma MDA and SOD Levels}

The mean plasma MDA and SOD levels of Wistar rats following high-cholesterol diet and BBLE intervention for 30 days revealed significant differences between both

Table 1. Phytochemical compounds screening of BBLE.

\begin{tabular}{lcc}
\hline $\begin{array}{c}\text { Phytochemical } \\
\text { Compounds }\end{array}$ & Reactions & Result \\
\hline Alkaloid & Green & - \\
Flavonoid & Brown & + \\
Triterpenoid & Green & - \\
Saponin & Foam & + \\
Phenol & Dark green & + \\
Tannin & Dark green & + \\
Steroid & Dark green blackish & + \\
\hline
\end{tabular}

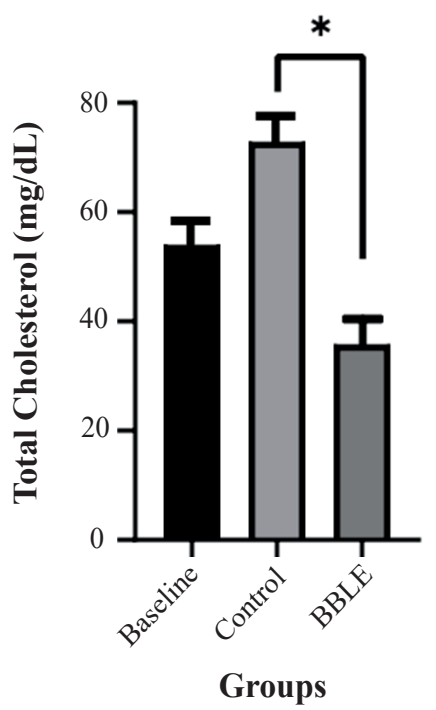

Figure 1. Total cholesterol levels of hypercholesterolemic Wistar rats $(\mathbf{n}=\mathbf{8})$. Expressed in mean $\pm \mathrm{SD}$; * significant difference $(p<0.05)$ between the two groups based on statistical tests with Independent T-Test.

groups $(p<0.05)$. When compared to the BBLE group, the average MDA plasma levels in the control group were higher, namely $29.40 \pm 8.60 \mathrm{~mol} / \mathrm{mL}$ compared to $12.41 \pm 5.17$ mol/L (Figure 3). In contrast to plasma MDA, SOD levels in the control group were lower at $19.2 \pm 5.98 \mathrm{U} /$ $\mathrm{mL}$ compared to $37.69 \pm 4.82 \mathrm{U} / \mathrm{mL}$ in the BBLE group (Figure 4). This implies that BBLE has a positive effect on lowering plasma MDA levels in the body as a result of a high-cholesterol diet and functions as an essential antioxidative agent in rats.

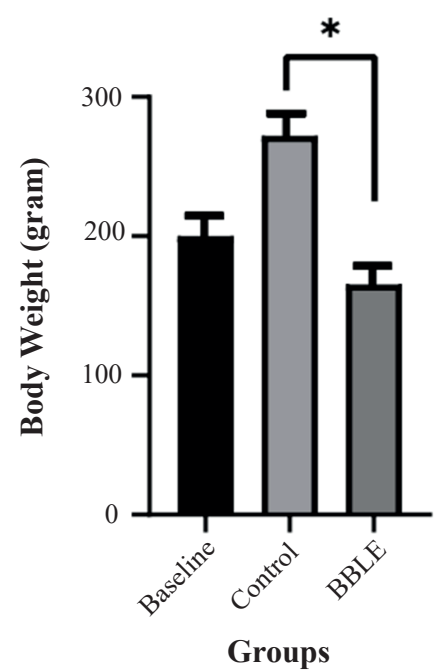

Figure 2. Body weight of hypercholesterolemic Wistar rats $(\mathbf{n}=8)$. Expressed in mean $\pm \mathrm{SD}$; *significant difference $(p<0.05)$ between the two groups based on statistical tests with Independent T-Test. 


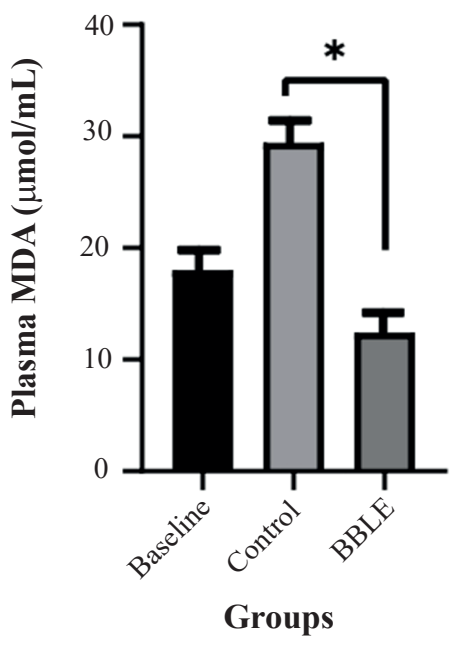

Figure 3. Plasma MDA levels of hypercholesterolemic Wistar rats $(\mathbf{n}=\mathbf{8})$. Expressed in mean $\pm \mathrm{SD}$; *significant difference $(p<0.05)$ between the two groups based on statistical tests with Independent T-Test.

\section{The Effect of BBLE on LH Levels}

The levels of LH varied substantially across treatments $(p<0.05)$. The control group's average of $25.34 \pm 2.18 \mathrm{mIU} /$ $\mathrm{mL}$ was lower than the BBLE group average of $47.84 \pm 3.62$ $\mathrm{mIU} / \mathrm{mL}$ (Figure 5), indicating that BBLE plays an important role in the mechanism of maintaining the hypothalamicpituitary axis by stimulating $\mathrm{LH}$.

Overall, all test variables in the BBLE group were close to the baseline levels measured in pre-intervention. Table 2 summarizes the findings from our observations.

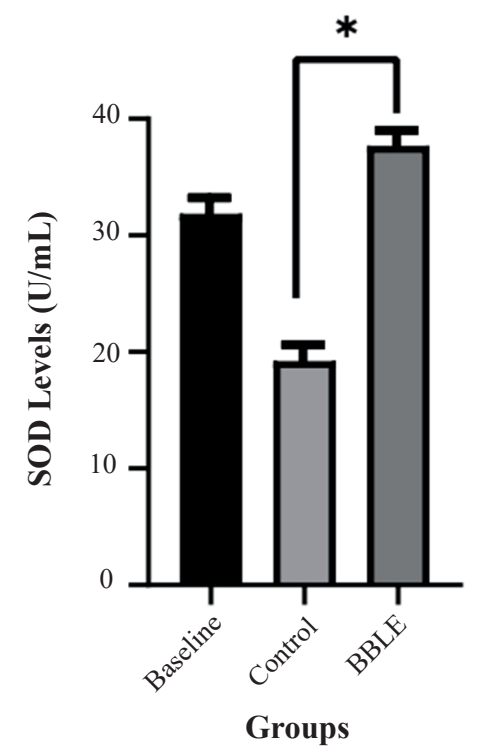

Figure 4. SOD levels of hypercholesterolemic Wistar rats $(n=8)$ Expressed in mean $\pm \mathrm{SD}$; *significant difference $(p<0.05)$ between the two groups based on statistical tests with Independent T-Test.

\section{Discussion}

The BBLE has the highest flavonoid concentration of the three major kinds of phytochemical compounds.(25) Flavonoids are a class of natural phenols found in many fruits and vegetables as well as traditional medicine (26) that offer health advantages via cell-mediated signaling, antioxidants, anti-inflammatory, neurological, and cardiovascular effects (27). Besides from that, that tannin is the second most abundant in our extract components.

The BBLE used in this study was effective at lowering total cholesterol levels in Wistar rats fed a highcholesterol diet. High cholesterol levels may increase the amount of fat in adipose tissue, leading to a increase in body weight. Consequently, the flavonoids in BBLE act as peroxisome proliferator-activated receptor (PPAR) ligands, decreasing the expression of the sterol regulatory elementbinding protein 1c (SREBP-1c) in the liver and, as a result, decreasing the formation of triglycerides in tissues.(28)

Plasma MDA and SOD levels are essential indicators for monitoring oxidative stress in the body induced by free radical toxicity, such as high-cholesterol diets.(2931) In our findings, we hypothesized that flavonoid levels had a substantial beneficial impact on high SOD levels, resulting in lower plasma MDA levels in the BBLE group. The flavonoid concentration of the BBLE is high, which may serve as antioxidants and promote cell regeneration caused to free radical damage. Flavonoids have a metabolic

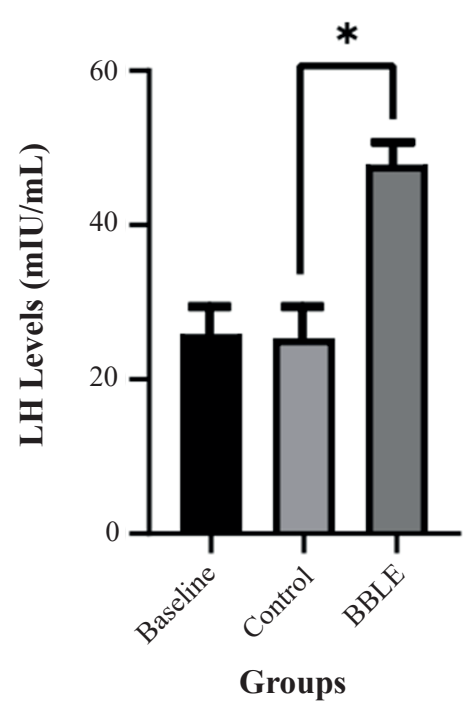

Figure 5. LH levels of hypercholesterolemic Wistar rats Expressed in mean $\pm \mathrm{SD}$; *significant difference $(p<0.05)$ between the two groups based on statistical tests with Independent T-Test. 
Table 2. MDA, SOD, LH, total cholesterol, and body weight of Wistar rats.

\begin{tabular}{lccc}
\hline \multicolumn{1}{c}{ Parameter } & Control & BBLE & p-value \\
\hline Malondialdehyde $(\mathrm{MDA})(\mu \mathrm{mol} / \mathrm{mL})$ & $29.40 \pm 8.60$ & $12.41 \pm 5.17$ & $0.01^{*}$ \\
SOD $(\mathrm{U} / \mathrm{mL})$ & $19.20 \pm 5.98$ & $37.69 \pm 4.82$ & $0.04^{*}$ \\
LH $(\mathrm{mIU} / \mathrm{mL})$ & $25.34 \pm 2.18$ & $47.84 \pm 3.62$ & $0.01^{*}$ \\
Total cholesterol $(\mathrm{mg} / \mathrm{dL})$ & $72.92 \pm 17.13$ & $35.86 \pm 1.15$ & $0.00^{*}$ \\
Body weight (gram) & $272 \pm 9.85$ & $165.38 \pm 5.73$ & $0.04^{*}$ \\
\hline
\end{tabular}

Results are presented as mean $\pm \mathrm{SD}$. * $p$-value was tested with Independent T-test with significance of $p<0.05$.

mechanism in cell membranes that includes trapping free radicals of unsaturated fatty acids and converting them into non-free radicals. As a consequence of these processes, lipid oxidation is decreased. In the chemical structure of flavonoids, ring B has a hydroxy group capable of donating hydrogen, which influences free radical stability.(32)

Increased levels of antioxidant enzymes induced by BBLE are capable of maintaining the hypothalamusperformance pituitary's in generating LH. SOD generation, by lowering negative feedback, was able to promote an increase in HPA axis activity.(33) The pituitary gland to release $\mathrm{LH}$, which in turn stimulates Leydig cells to produce testosterone through Steroidogenesis.(34)

Based on the parameters tested, there was a correlation between a near-baseline decrease in total cholesterol and an increase in antioxidant enzymes and LH secretion. Clinical investigations/research regarding the synergistic mechanism of the herbal ingredients that we use are still needed to be able to verify the combination of phytochemical compounds reported against side effects that can be caused and increase their pharmacological potential as new phytomedicine substances.(35)

\section{Conclusion}

The BBLE has a significant effect as an antihypercholesterolemic and antioxidant. The presence of phytochemical compounds from BBLE is effective in preventing the increase in total cholesterol and plasma MDA, as well as maintaining SOD and LH levels. This findings suggest that BBLE has a potential effect to improve male fertility through positive stimulation of the hypothalamicpituitary axis to produce LH. Further research is needed, especially on the role of BBLE on several molecular markers in testicular tissue, to provide comprehensive knowledge about the impact of BBLE on the pathophysiology of male infertility caused by hypercholesterolemic.

\section{Acknowledgments}

The author thanks Dr. Satuman, S.Si., M.Kes from the Physiology Laboratory, Faculty of Medicine, Brawijaya University, East Java for analysis procedures. The authors would like to provided funding assistance from the Universitas Dhyana Pura and Community Service Institute (LP2M) with Contract Number: 037/UNDHIRA-LP2M/ Lit./2020.

\section{Authors Contribution}

IGW and IMJ planned the research concept and supervised the study; IGW, IMJ, and AAAPP prepared the research guideline; IWR, AAAPP, PAW, and LPW conducted the study and collected samples; PAW and LPW and did data analysis and wrote the manuscript; IGW did the final proofread of the manuscript.

\section{References}

1. Lykkesfeldt J. Malondialdehyde as biomarker of oxidative damage to lipids caused by smoking. Clin Chim Acta. 2007; 380: 50-8.

2. Kumar R, Venkatesh S, Kumar M, Tanwar M, Shasmsi MB, Kumar $\mathrm{R}$, et al. Oxidative stress and sperm mitochondrial DNA mutation in idiopathic oligoasthenozoospermic men. Indian $\mathrm{J}$ Biochem Biophys. 2009; 46: 172-7.

3. Ito F, Sono Y, Ito T. Measurement and clinical significance of lipid peroxidation as a biomarker of oxidative stress: oxidative stress in diabetes, atherosclerosis, and chronic inflammation. Antioxidants. 2019; 8: 72. doi: 10.3390/antiox8030072.

4. Pieme CA, Tatangmo JA, Simo G, Biapa Nya PC, Ama Moor VJ, Moukette Moukette B, et al. Relationship between hyperglycemia, antioxidant capacity and some enzymatic and non-enzymatic antioxidants in African patients with type 2 diabetes. BMC Res Notes. 2017; 10: 141. doi: 10.1186/s13104-017-2463-6.

5. Milanlioglu A, Aslan M, Ozkol H, Çilingir V, Nuri Aydın M, Karadas S. S98erum antioxidant enzymes activities and oxidative stress levels in patients with acute ischemic stroke: influence on 
neurological status and outcome. Wien Klin Wochenschr. 2016; 128: $169-74$.

6. Sharebiani H, Fazeli B, Maniscalco R, Ligi D, Mannello F. The imbalance among oxidative biomarkers and antioxidant defense systems in thromboangiitis obliterans (Winiwarter-Buerger Disease). J Clin Med. 2020; 9: 1036. doi: 10.3390/jcm9041036.

7. Yang RL, Shi YH, Hao G, Li W, Le GW. Increasing oxidative stress with progressive hyperlipidemia in human: relation between malondialdehyde and atherogenic index. J Clin Biochem Nutr. 2008; 43: 154-8.

8. Nita M, Grzybowski A. The role of the reactive oxygen species and oxidative stress in the pathomechanism of the age-related ocular diseases and other pathologies of the anterior and posterior eye segments in adults. Oxid Med Cell Longev. 2016; 2016: 3164734. doi: 10.1155/2016/3164734.

9. Svechnikov K, Landreh L, Weisser J, Izzo G, Colón E, Svechnikov $\mathrm{I}$, et al. Origin, development and regulation of human leydig cells. horm res paediatr. 2010; 73: 93-101.

10. Permatasari AAAP, Sari NKY, Widhiantara IG. Histopathology of the muscle corpus kavernosum Wistar rat (Rattus norvegicus) hyperlipidemia. Metamorf J Biol Sci. 2018; 5: 254-8.

11. Rosiana IW, Widhiantara IG. Lumen and endotelium penile dorsal arteries hystology of Wistar rats (Rattus novergicus) induced by high-fat diet. Metamorf J Biol Sci. 2020; 7: 73-9.

12. Rahardjo SS. Review tanaman Sembung [Blumea balsamifera (L.)]. Proc Mulawarman Pharm Conf. 2016; 3: 18-28.

13. Pang Y, Wang D, Fan Z, Chen X, Yu F, Hu X, et al. Blumea balsamifera - a phytochemical and pharmacological review. Molecules. 2014; 19: 9453-77.

14. Widhiantara IG, Permatasari AAAP, Wiradana PA. The Effect of Sembung Leaf Extract (Blumea balsamifera) On The Number and Diameter of Rats Leydig Cells Induced By High-Fat Diet. Plant Arch. 2021; 21: 356-61.

15. Widhiantara IG, Permatasari AAAP, Siswanto FM, Dewi NPES, Sembung (Blumea balsamifera) leaf extract improves testis histology of high-fat diet induced rats. J Bioteknol Biosains Indones. 2018; 5: 111-8.

16. Eriadi A, Uthia R, Novita R. The effect of ethanol extract of Sembung leaves (Blumea balsamifera (L.) DC.) on blood glucose levels and pancreatic histopathology of male white mice induced by alloxan. $\mathrm{J}$ Farm Higea. 2017; 9: 127-39.

17. Ikalinus R, Widyastuti S, Eka Setiasih N. Phytochemical screening ethanol extracts skin stem moringa (Moringa oleifera). Indones Med Veterinus. 2015; 4: 71-9.

18. Hossain MA, AL-Raqmi KAS, AL-Mijizy ZH, Weli AM, Al-Riyami Q. Study of total phenol, flavonoids contents and phytochemical screening of various leaves crude extracts of locally grown Thymus vulgaris. Asian Pac J Trop Biomed. 2013; 3: 705-10.

19. Love J, Simons CR. Acid hydrolysis of saponins extracted in tincture. PLoS One. 2020; 15: 1-17. doi: 10.1371/journal.pone.0244654.

20. Sri Sulasmi E, Saptasari M, Mawaddah K, Ama Zulfia F. Tannin identification of 4 species pterydophyta from Baluran National
Park. J Phys Conf Ser. 2019; 1241: 012002. doi: 10.1088/17426596/1241/1/012002.

21. Astiti NPA, Sudirga SK, Ramona Y. Analysis of phenolic and tannin contents in the methanol extract of sweet and sour star fruit plants (Averrhoa carambola L) leaves commonly used as raw materials of Lawar (A Balinese Traditional Food). Adv Trop Biodivers Environ Sci. 2019; 3: 5-7.

22. Ministry of Health Republic of Indonesia. Farmakope Herbal Indonesia Edisi II. Jakarta: Ministry of Health Republic of Indonesia; 2017.

23. Lamont BJ, Waters MF, Andrikopoulos S. A low-carbohydrate high-fat diet increases weight gain and does not improve glucose tolerance, insulin secretion or $\beta$-cell mass in NZO mice. Nutr Diabetes. 2016; 6: e194. doi: 10.1038/nutd.2016.2.

24. Beale KEL, Murphy KG, Harrison EK, Kerton AJ, Ghatei MA, Bloom SR, et al. Accurate measurement of body weight and food intake in environmentally enriched male Wistar rats. Obesity. 2011; 19: 1715-21.

25. Widhiantara IG, Jawi IM. Phytochemical composition and health properties of Sembung plant (Blumea balsamifera): A review. Vet World. 2021; 14: 1185-96.

26. Saura-Calixto F, Goñi I. Definition of the mediterranean diet based on bioactive compounds. Crit Rev Food Sci Nutr. 2009; 49: 145-52.

27. Miller MG, Shukitt-Hale B. Berry fruit enhances beneficial signaling in the brain. J Agric Food Chem. 2012; 60: 5709-15.

28. Khalilpourfarshbafi M, Gholami K, Murugan DD, Abdul Sattar MZ, Abdullah NA. Differential effects of dietary flavonoids on adipogenesis. Eur J Nutr. 2019; 58: 5-25.

29. Ngestiningsih D, Rahayu RA, Batubara L. Effect of superoxide dismutase (SOD) supplementation on plasma levels of malondialdehyde (MDA), total cholesterol and LDL cholesterol in the elderly. J Biomed Transl Res. 2019; 5: 29-33.

30. Mao C, Yuan JQ, Lv YB, Gao X, Yin ZX, Kraus VB, et al. Associations between superoxide dismutase, malondialdehyde and all-cause mortality in older adults: a community-based cohort study. BMC Geriatr. 2019; 19: 104. doi: 10.1186/s12877-019-1109-z.

31. Rizal A, Sandra F, Fadlan MR, Sargowo D. Ganoderma lucidum polysaccharide peptide reduce inflammation and oxidative stress in patient with atrial fibrillation. Indones Biomed J. 2020; 12(4): $384-9$.

32. Panche AN, Diwan AD, Chandra SR. Flavonoids: an overview. J Nutr Sci. 2016; 5: e47. doi: 10.1017/jns.2016.41.

33. Spiers JG, Chen HJC, Sernia C, Lavidis NA. Activation of the hypothalamic-pituitary-adrenal stress axis induces cellular oxidative stress. Front Neurosci. 2015; 8: 456. doi: 10.3389/fnins.2014.00456.

34. Widhiantara IG, Putri AAA, Permatasari, Rosiana IW, Wiradana PA, Satriyasa BK. Steroidogenesis mechanism, disruption factor, gene function, and role in male fertility : a minirReview. Indian J Forensic Med Toxicol. 2021; 15: 1456-68.

35. Yang Y, Zhang Z, Li S, Ye X, Li X, He K. Synergy effects of herb extracts: Pharmacokinetics and pharmacodynamic basis. Fitoterapia. 2014; 92: 133-47. 